\title{
Association Between Gastric Emptying Time and Incidence of Cardiovascular Diseases in Subjects With Diabetes
}

\author{
Hyung-Min Park, Seon-Young Park, ${ }^{*}$ Jin Ook Chung, ${ }^{*}$ Dong Hyuk Cho, Chang-Hwan Park, Hyun-Soo Kim, Dong Jin Chung, \\ Sung-Kyu Choi, Jong-Sun Rew, and Min Young Chung \\ Department of Internal Medicine, Chonnam National University Medical School, Gwangju, Korea
}

\section{Background/Aims}

Delayed gastric emptying (GE) is associated with high morbidity and mortality in subjects with diabetes. The aim of this study is to investigate associations between GE time and the major cardiovascular events (coronary heart diseases and ischemic stroke) in diabetic subjects with upper gastrointestinal (UGI) symptoms.

\section{Methods}

Among 259 subjects with chronic UGI symptoms who underwent gastric emptying study (GES) over 13 years, 122 diabetic subjects without gastric surgery and/or rapid GE were enrolled in this study. We also gathered data about baseline demographics, clinical characteristics, estimated GE half-time (GE T/1/2) and incidence of cardiovascular events following GES.

\section{Results}

The mean age of subjects was $64.0 \pm 17.4$ years. There were 86 women and 104 subjects with type 2 diabetes. There were 52 (42.6\%) subjects with normal GE, 50 (41.0\%) subjects with mild delayed $\mathrm{GE}$, and $20(16.4 \%)$ subjects with marked delayed GE. During follow-up (median, 207 weeks), cardiovascular events occurred in $7(13.5 \%)$ subjects with normal GE, $4(8.0 \%)$ subjects with mild delayed GE and $7(35.0 \%)$ subjects with marked GE $(P=0.015)$. Univariate analysis showed that $\mathrm{GE} \mathrm{T}_{1 / 2}$ was significantly associated with incidence of cardiovascular events (crude $O R, 1.74 ; 95 \% \mathrm{Cl}, 1.12-2.69 ; P=0.014$ ). In a multivariate model, association between GE $T_{1 / 2}$ and incidence of cardiovascular events remained statistically significant after adjustment for baseline characteristics and comorbidities (adjusted OR, 1.94; $95 \% \mathrm{Cl}, 1.21-3.12 ; P=0.006$ ).

\section{Conclusion}

A delay of GE was associated with an increased incidence of cardiovascular events in diabetic subjects with chronic UGI symptoms. (J Neurogastroenterol Motil 2019;25:387-393)

Key Words

Coronary disease; Diabetes Mellitus; Emptying, gastric; Stroke

Received: February 14, 2019 Revised: April 11, 2019 Accepted: May 6, 2019

(a) This is an Open Access article distributed under the terms of the Creative Commons Attribution Non-Commercial License (http://creativecommons. org/licenses/by-nc/4.0) which permits unrestricted non-commercial use, distribution, and reproduction in any medium, provided the original work is properly cited.

${ }^{*}$ Correspondence: Seon-Young Park and Jin Ook Chung are equally responsible for this study. Seon-Young Park, MD, PhD Chonnam National University Medical School, 160 Baekseo-ro, Dong-gu, Gwangju 61469, Korea Tel: +82-62-220-6296, Fax: +82-62-225-8578, E-mail: drpsy@naver.com Jin Ook Chung, MD, PhD Chonnam National University Medical School, 160 Baekseo-ro, Dong-gu, Gwangju 61469, Korea Tel: +82-62-220-6296, Fax: +82-62-225-8578, E-mail: imagine-jjo@hanmail.net 


\section{Introduction}

GI disorders have been more common among the diabetic subjects as the incidence of diabetes has increased. The entire GI tract can be affected by diabetes and common GI complications include abnormal GI (esophageal, gastric, or enteric) motility, nonalcoholic fatty liver disease, and glycogenic hepatitis. ${ }^{1}$ Among GI complications, a delay in gastric emptying (GE) occurs in subjects with longstanding type 1 or type 2 diabetes. ${ }^{2}$ Several cross-sectional studies showed that 30-50\% of long-standing diabetic outpatients had delayed GE, which may cause chronic upper gastrointestinal (UGI) symptoms such as nausea, vomiting, postprandial fullness, and early satiety. ${ }^{3-5}$

The pathophysiology of a delay in GE is incompletely understood and considered as multifactorial: impaired glycemic control, loss of the interstitial cells of Cajal and autonomic neuropathy. Diabetic autonomic neuropathy include extrinsic vagal neuropathy and reduction of intrinsic inhibitory neurons that mediate gastric accommodation or contractions, ${ }^{2,6}$ which may be overlapped with cardiac autonomic neuropathy as one of the risk factors for cardiovascular diseases in diabetes. ${ }^{7}$ Although several cross-sectional studies reported that diabetic subjects with delayed GE had more frequently hypertension and coronary artery disease than those without delayed $\mathrm{GE}^{8,9}$ there is limited data on the relationships between the degree of a delay in GE and the incidence of cardiovascular events following GE study in subjects with diabetes to date.

In this study, we aim to investigate associations between GE time and the major cardiovascular events (coronary heart diseases and ischemic stroke) after GE study in diabetic subjects with UGI symptoms.

\section{Materials and Methods}

We designed this retrospective observational study to investigate the incidence of cardiovascular disease in diabetic subjects with UGI symptoms after GE study. The present study was conducted in accordance with the Ethical Guidelines of the Declaration of Helsinki. This study was approved by the Institutional Review Board of Chonnam National University Hospital (No. CNUH2018-245). We had requested the list of subjects who underwent GE study between January 2001 and December 2017 to the department of medical records in our center. We found 259 subjects who had undergone GE study for the evaluation of chronic UGI symptoms between April 2004 and December 2017. Among them, there were 165 subjects with diabetes. Inclusion criteria were (1) subjects with diabetes $\geq 18$ years old; (2) the absence of known gastric obstruction on endoscopy or UGI series. We performed gastric emptying study (GES) using ${ }^{99 \mathrm{~m}}$ Technetium sulfur colloid radiolabeled boiled eggs. ${ }^{10}$ All subjects were obtained in the anterior and posterior projection immediately and at 5, 10, 20, 30, $45,60,90$, and 120 minutes after meal ingestion while the subjects were standing. Scintigraphic images were obtained with a large field of view of the gamma camera using a low energy all-purpose collimator with a $20 \%$ energy window setting centered at $140 \mathrm{keV}$. Patients were allowed to sit in a chair between the standing images acquisitions. We excluded patients with "rapid GE" which was defined as $<30 \%$ retention at 1 hour or previous gastric surgery. We estimated GE half-time ( $\mathrm{GE} \mathrm{T}_{1 / 2}$ ) using linear interpolation using all the scan times over the image sequence. GE was divided into 3 grades according to time. "Normal GE" was defined as GE $\mathrm{T}_{1 / 2}<$ 72 minutes, "mild delayed GE" as GE $T_{1 / 2} \geq 72$ to $<144$ minutes, and "marked delayed GE" as GE $\mathrm{T}_{1 / 2}>144$ minutes. ${ }^{11,12}$

We collected demographic data for enrolled patients when they underwent GES. Definitions of comorbid conditions were as follows; hypertension ( $\geq 140 / 90 \mathrm{mmHg}$ or antihypertensive drugs), dyslipidemia (serum total cholesterol level $\geq 6.22 \mathrm{mmol} /$ $\mathrm{L}$, serum low-density lipoprotein cholesterol level $\geq 4.14 \mathrm{mmol} /$ $\mathrm{L}$, serum triglycerides level $\geq 2.27 \mathrm{mmol} / \mathrm{L}$, serum high-density lipoprotein cholesterol level $<1.04 \mathrm{mmol} / \mathrm{L}$ or taking the lipidregulating drugs), ${ }^{13}$ chronic kidney disease (serum creatinine level $>133 \mu \mathrm{mol} / \mathrm{L}$ in men and serum creatinine level $>106 \mu \mathrm{mol} /$ 1 in women) in study subjects. We collected the data on carotid intima-media thickness (IMT) and ankle-brachial pressure index (ABPI). Carotid IMT was measured on the far wall of right and left common carotid artery at a site approximately $10 \mathrm{~mm}$ proximal to the carotid bulb, using IMT measurement software Intimascope (Media Cross Co. Ltd, Tokyo, Japan). We used the mean values of the right and left carotid IMT. Plaque was defined when the vessel wall thickness was $>1.5 \mathrm{~mm}$ or when protrusion into the lumen was $50 \%$ thicker than the surrounding area. ABPI was calculated automatically in the supine position using the VaSeraTM VS-1000 (Fukuda Densi, Tokyo, Japan) with cuffs around both arms and ankles. The lowest value of the left and right ABPI was used for analysis. We defined "previous cardiovascular diseases," which were assessed by reports of cardiologists, neurologists, and diabetologists who evaluated the patients based on clinical symptoms and objective examinations according to international guidelines.

The outcomes for the present study were the occurrence of coronary heart disease and ischemic stroke after GES. Coronary 
heart disease was defined on the basis of myocardial infarction, angina pectoris or ischemic heart disease, coronary artery angioplasty, or new pathological findings coded using Minnesota codes 1.1 to 3, 4.1 to 4 , and 5.1 to 3 in the resting electrocardiogram. ${ }^{14} \mathrm{~A}$ diagnosis of ischemic stroke was based on medical records, if pathological findings such as ischemic stroke on computed tomography or an area of low signal intensity measuring at least $3 \mathrm{~mm}$ on T1-weighted images and a hyper-intense lesion on T2-weighted images on magnetic resonance imaging of the brain had been documented. ${ }^{15}$ Cardiovascular events were considered a composite of coronary heart disease and ischemic stroke. Data on the incidence of cardiovascular events after GES were collected from electronic medical records until Aug 2018.

\section{Statistical Methods}

Data was expressed as the mean $\pm \mathrm{SD}$, unless otherwise stated. Variables with a skewed distribution were log-transformed prior to analysis, and the data were represented as geometric mean (95\% CI). Continuous variables were analyzed using the Mann-Whitney $U$ test or Student's $t$ test. Pearson' Chi-squared test was used to compare the incidence of cardiovascular events among each group. Multivariate

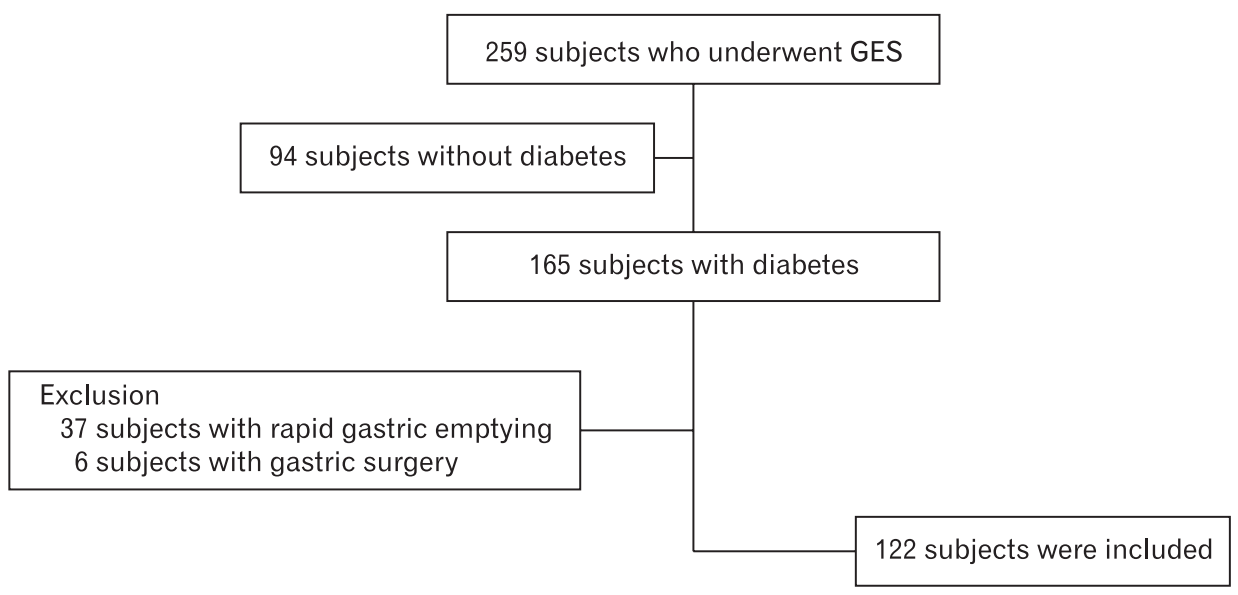

Figure. Flowsheet of this study. Among 259 subjects who underwent gastric emptying (GE) study, there were 165 subjects with diabetes. After exclusion of 43 subjects with rapid GE or gastric surgery, 122 subjects with diabetes were enrolled in this study. GES, gastric emptying study.

Table 1. Baseline Demographics and Clinical Factors in 122 Subjects With Diabetes

\begin{tabular}{|c|c|c|c|c|}
\hline Variables & $\begin{array}{l}\text { Subjects with normal GE } \\
\qquad(\mathrm{n}=52)\end{array}$ & $\begin{array}{c}\text { Subjects with mild } \\
\text { delayed GE }(\mathrm{n}=50)\end{array}$ & $\begin{array}{l}\text { Subjects with marked } \\
\text { delayed GE }(\mathrm{n}=20)\end{array}$ & $P$-value \\
\hline Type 2 Diabetes & $48(92.3)$ & $42(84.0)$ & $14(70.0)$ & 0.054 \\
\hline Duration of diabetes (yr) & $8.2(6.6-10.1)$ & $10.5(8.5-12.9)$ & $9.4(6.7-13.2)$ & 0.267 \\
\hline Female & $37(71.2)$ & $35(70.0)$ & $14(70.0)$ & 0.990 \\
\hline Age (yr) & $62.1 \pm 15.8$ & $60.6 \pm 18.2$ & $52.4 \pm 18.6$ & 0.098 \\
\hline $\operatorname{BMI}\left(\mathrm{kg} / \mathrm{m}^{2}\right)$ & $23.2 \pm 4.1$ & $23.2 \pm 3.7$ & $22.8 \pm 4.5$ & 0.920 \\
\hline Smoking & $8(15.4)$ & $6(12.0)$ & $2(10.0)$ & 0.795 \\
\hline Glycated hemoglobin (\%) & $8.2 \pm 1.5$ & $8.6 \pm 2.4$ & $9.0 \pm 2.2$ & 0.293 \\
\hline \multicolumn{5}{|l|}{ Comorbid diseases } \\
\hline Hypertension & $27(51.9)$ & $21(42.0)$ & $11(55.0)$ & 0.490 \\
\hline Previous cardiovascular disease & $9(17.3)$ & $8(16.0)$ & $1(5.0)$ & 0.387 \\
\hline Chronic kidney disease & $16(30.8)$ & $18(36.0)$ & $6(30.0)$ & 0.818 \\
\hline Dyslipidemia & $40(76.9)$ & $31(62.0)$ & $16(80.0)$ & 0.161 \\
\hline \multicolumn{5}{|l|}{ Upper gastrointestinal symptoms } \\
\hline Nausea & $30(57.7)$ & $28(56.0)$ & $11(55.0)$ & 0.974 \\
\hline Vomiting & $26(50.0)$ & $15(30.0)$ & $12(60.0)$ & 0.033 \\
\hline Bloating & $1(1.9)$ & $1(2.0)$ & $0(0.0)$ & 0.640 \\
\hline Epigastric discomfort & $13(25.0)$ & $11(22.0)$ & $6(30.0)$ & 0.778 \\
\hline
\end{tabular}

BMI, body mass index; GE, gastric emptying.

"Normal GE" was defined as GE time $<72$ minutes, "mild delayed GE" as $\geq 72$ to $<144$ minutes and "marked delayed GE" as $>144$ minutes.

Values are given as the mean $\pm \mathrm{SD}$, geometric mean $(95 \% \mathrm{CI})$, or $\mathrm{n}(\%)$. 
logistic regression model was used to assess whether clinical variables at diagnosis were associated with the risk of incidence of cardiovascular events after GE studies. Statistical analysis was performed using SPSS software version 20.0 (IBM Corp, Armonk, NY, USA). A $P$-value of less than 0.05 considered statistically significant.

\section{Results}

There were 259 subjects who underwent GE studies for the evaluation of chronic UGI symptoms between April 2004 and December 2017. Among them, there were 165 diabetic subjects. We excluded 37 subjects with rapid GE and 6 subjects who had undergone gastric surgery. Finally, 122 subjects were included in this study (Figure). The mean age of enrolled patients was $64.0 \pm 17.4$ years. There were 86 women $(70.5 \%)$ and 104 (85.2\%) with type 2 diabetes. Eight subjects had a history of coronary heart disease, 7 subjects had a history of ischemic stroke, and 3 subjects had both histories of coronary heart disease and ischemic stroke.

The most common presenting symptoms were nausea $(56.6 \%)$ and vomiting (43.4\%). There were 52 subjects (42.6\%) with "normal GE” and 70 subjects (57.4\%) with "delayed GE.” Among subjects with delayed GE, 20 patients had "marked delayed GE."

Table 1 demonstrates the baseline demographic factors and clinical characteristics in the enrolled subjects. There were 48 (92.3\%) subjects with type 2 diabetes in "normal GE," 42 (84.0\%) subjects with type 2 diabetes in "mild delayed GE," and $14(70.0 \%)$ subjects with type 2 diabetes in marked "delayed GE" $(P=0.054)$. Among subjects with marked delayed GE, $60.0 \%$ subjects had vomiting, while $50.0 \%$ subjects with normal GE and $30.0 \%$ subjects with mild $\mathrm{GE}$ had vomiting $(P=0.033)$.

Among 122 subjects, 76 subjects had ABPI measurements and 42 had carotid IMT measurements. There was no significant differences in ABPI according to baseline characteristics (normal $\mathrm{GE}[\mathrm{n}=33], 1.09 \pm 0.14$; mild delayed GE $[\mathrm{n}=29], 1.04 \pm$ 0.14 ; marked delayed GE $[\mathrm{n}=14], 1.11 \pm 0.10 \mathrm{~mm} ; P=0.207$ ). In addition, there were no significant differences in carotid IMT and the presence of plaque according to baseline characteristics (normal GE, $0.86 \pm 0.32 \mathrm{~mm}$; mild delayed GE, $0.86 \pm 0.29$ mm; marked delayed GE, $0.82 \pm 0.28 \mathrm{~mm} ; P=0.938$ and normal GE, 5/20 (25.0\%); mild delayed GE, 3/14 (21.4\%); marked delayed GE $3 / 8(37.5 \%) ; P=0.702$, respectively).

\section{Incidence of Cardiovascular Events in Diabetic Patients With Upper Gastrointestinal Symptoms}

There were 18 subjects with cardiovascular events during follow-up period [median (quartile), 207 weeks (range, 86-390)]. Ischemic stroke occurred in 8 subjects and coronary heart disease occurred in 10 subjects.

From the medical records of 122 subjects, we identified 9 subjects ( 3 with normal GE, 4 with mild delayed GE and 2 with marked delayed GE) who died due to complications of ischemic stroke $(\mathrm{n}=2)$, uncontrolled infection $(\mathrm{n}=4)$, malignancy $(\mathrm{n}=2)$, and postoperative complication $(\mathrm{n}=1)$.

\section{Baseline Demographics and Clinical Factors Between Subjects Without Cardiovascular Events and Subjects With Cardiovascular Events After Gastric Emptying Study}

There was no significant difference in baseline demographics between subjects without cardiovascular events and subjects with cardiovascular events (Table 2). However, there was a significant difference in previous history of cardiovascular diseases between the

Table 2. Baseline Demographics and Clinical Factors Between Subjects Without Cardiovascular Events and Subjects With Cardiovascular Events After Gastric Emptying Study

\begin{tabular}{|c|c|c|c|}
\hline Variables & $\begin{array}{l}\text { Subjects without } \\
\text { cardiovascular } \\
\text { events } \\
(\mathrm{n}=104)\end{array}$ & $\begin{array}{l}\text { Subjects with } \\
\text { cardiovascular } \\
\text { events } \\
(\mathrm{n}=18)\end{array}$ & $P$-value \\
\hline Type 2 diabetes & $88(84.6)$ & $16(88.9)$ & 0.999 \\
\hline $\begin{array}{l}\text { Duration of } \\
\text { diabetes (yr) }\end{array}$ & $9.0(7.7-10.4)$ & $11.2(7.8-16.0)$ & 0.261 \\
\hline Female & $76(73.1)$ & $10(55.6)$ & 0.132 \\
\hline Age (yr) & $59.2 \pm 18.1$ & $64.0 \pm 12.8$ & 0.178 \\
\hline $\operatorname{BMI}\left(\mathrm{kg} / \mathrm{m}^{2}\right)$ & $23.2 \pm 4.1$ & $22.5 \pm 3.5$ & 0.496 \\
\hline Smoking & $11(10.6)$ & $5(27.8)$ & 0.061 \\
\hline $\begin{array}{l}\text { Glycated } \\
\text { hemoglobin (\%) }\end{array}$ & $8.5 \pm 2.1$ & $8.6 \pm 1.9$ & 0.831 \\
\hline \multicolumn{4}{|l|}{ Comorbid diseases } \\
\hline Hypertension & $49(47.1)$ & $10(55.6)$ & 0.508 \\
\hline $\begin{array}{l}\text { Previous cardio- } \\
\text { vascular disease }\end{array}$ & $11(10.6)$ & $7(38.9)$ & 0.006 \\
\hline $\begin{array}{l}\text { Chronic kidney } \\
\text { disease }\end{array}$ & $25(24.0)$ & $6(33.3)$ & 0.393 \\
\hline Dyslipidemia & $76(73.1)$ & $11(61.1)$ & 0.300 \\
\hline Degree of GE & & & 0.015 \\
\hline Normal & $45(43.3)$ & $7(38.9)$ & \\
\hline Mild & $46(44.2)$ & $4(22.2)$ & \\
\hline Marked & $13(12.5)$ & $7(38.9)$ & \\
\hline $\mathrm{GE} \mathrm{T}_{1 / 2}(\min )$ & $83.4(72.3-96.2)$ & $138.7(98.2-195.4)$ & 0.008 \\
\hline
\end{tabular}

BMI, body mass index; GE, gastric emptying; GE $\mathrm{T}_{1 / 2}$, gastric emptying halftime.

Values are given as the mean $\pm \mathrm{SD}$, geometric mean $(95 \% \mathrm{CI})$, or $\mathrm{n}(\%)$. 
2 groups $(P=0.006)$. There was a significant difference in degree of $\mathrm{GE} \mathrm{T}_{1 / 2}$ between the 2 groups $(P=0.015)$. In addition, subjects with cardiovascular events had longer $G E T_{1 / 2}$ than those without cardiovascular events after GE study $(P=0.008$, Table 2$)$.

Among subjects with cardiovascular events after GE study, subjects with new-onset cardiovascular events (geometric mean [95\% CI], $227.9 \mathrm{~min}$ [113.1-459.4]) had longer $\mathrm{T}_{1 / 2} \mathrm{GE}$ than patients with both previous history of cardiovascular disease and cardiovascular events during follow-up period (63.4 min [range, 26.4-152.8], $P=0.044)$.

\section{Univariate and Multivariate Analysis of Risk Factors for Incidence of Cardiovascular Events After Gastric Emptying Study}

In univariate analysis, GE $T_{1 / 2}$ was significantly associated with incidence of cardiovascular events (crude odds ratio [OR], 1.74; 95\% CI, 1.12-2.69; $P=0.014$ ). In a multivariate model adjusted by baseline characteristics and comorbidities, GE $T_{1 / 2}$ and previous history of cardiovascular disease were significantly associated with incidence of cardiovascular events (adjusted odds ratio [aOR], 1.94; 95\% CI, 1.21-3.12; $P=0.006$ and aOR, 6.98; 95\% CI, $1.98-24.60 ; P=0.003$, respectively) (Table 3).
We further investigated the relationship between GE $\mathrm{T}_{1 / 2}$ and cardiovascular events in 104 subjects without previous history of cardiovascular disease. Univariate analysis showed that $\mathrm{GE} \mathrm{T}_{1 / 2}$ was significantly associated with incidence of new-onset cardiovascular events (cOR, 3.33; 95\% CI, 1.65-6.75; $P=0.001$ ). In a multivariate model adjusted by baseline characteristics and comorbidities (in Table 3), $\mathrm{T}_{1 / 2} \mathrm{GE}$ was significantly associated with incidence of newonset cardiovascular events (aOR, 2.99; 95\% CI, 1.49-6.01; $P=$ $0.002)$.

\section{Discussion}

In this study, cardiovascular events occurred in 18 subjects during 207 weeks of follow-up period. Ischemic stroke occurred in 8 subjects and coronary heart disease occurred in 10 subjects. In addition, GE time was independently associated with incidence of cardiovascular events after adjustment for comorbidities.

The subjects with long standing diabetes mellitus may have variable UGI symptoms including nausea, vomiting, early satiety, or bloating. Several studies showed the poor relationship with UGI symptoms and GE. ${ }^{4,16,17}$ Furthermore, symptoms of delayed GE overlap with those of rapid GE or functional dyspepsia. ${ }^{18}$ Previous

Table 3. Clinical Factors for Cardiovascular Events in Diabetic Subjects With Upper Gastrointestinal Symptoms

\begin{tabular}{|c|c|c|c|c|c|c|}
\hline \multirow{2}{*}{ Variables } & \multicolumn{2}{|c|}{ Unadjusted } & \multicolumn{2}{|c|}{ Model 1} & \multicolumn{2}{|c|}{ Model 2} \\
\hline & cOR $(95 \% \mathrm{CI})$ & $P$-value & $\mathrm{aOR}(95 \% \mathrm{CI})$ & $P$-value & $\mathrm{aOR}(95 \% \mathrm{CI})$ & $P$-value \\
\hline Age (yr) & $1.02(0.99-1.05)$ & 0.280 & & & & \\
\hline Male & $2.17(0.78-6.06)$ & 0.138 & & & & \\
\hline $\mathrm{BMI}\left(\mathrm{kg} / \mathrm{m}^{2}\right)$ & $0.95(0.83-1.09)$ & 0.493 & & & & \\
\hline Subtypes of diabetes & & 0.639 & & & & \\
\hline Type 1 & 1 & & & & & \\
\hline Type 2 & $1.46(0.31-6.95)$ & & & & & \\
\hline Duration of diabetes (yr) & $1.03(0.97-1.09)$ & 0.396 & & & & \\
\hline Glycated hemoglobin (\%) & $1.03(0.81-1.31)$ & 0.830 & & & & \\
\hline Smoking & $3.25(0.97-10.86)$ & 0.055 & & & & \\
\hline \multicolumn{7}{|l|}{ Comorbid diseases } \\
\hline Hypertension & $1.40(0.51-3.84)$ & 0.509 & & & & \\
\hline Previous cardiovascular disease & $5.38(1.73-16.74)$ & 0.004 & & & $6.98(1.98-24.60)$ & 0.003 \\
\hline Chronic kidney disease & $2.36(0.85-6.50)$ & 0.098 & & & & \\
\hline Dyslipidemia & $1.73(0.61-4.90)$ & 0.304 & & & & \\
\hline \multicolumn{7}{|l|}{ Gastric GE time } \\
\hline $\operatorname{Ln}\left(\mathrm{GE} \mathrm{T}_{1 / 2}\right),+1 \mathrm{SD}$ & $1.74(1.12-2.69)$ & 0.014 & $1.63(1.05-2.53)$ & 0.029 & $1.94(1.21-3.12)$ & 0.006 \\
\hline
\end{tabular}

cOR, crude odds ratio; aOR, adjusted odds ratio; CI, confidence interval; BMI, body mass index; $\mathrm{GE}_{\mathrm{T} / 2,}$ gastric emptying half-time; Ln, natural logarithm; SD, standard deviation.

Model 1, adjusted by age, gender, BMI, and habit of smoking.

Model 2, adjusted by age, gender, BMI, habit of smoking, duration of diabetes, glycated hemoglobin, hypertension, chronic kidney disease, dyslipidemia, and previous history of cardiovascular disease.

Odds ratio was calculated for any $1 \mathrm{SD}$ increase in $\mathrm{Ln}\left(\mathrm{GE} \mathrm{T}_{1 / 2}\right)$. 
studies showed that $36 \%$ of diabetic subjects had delayed GE and $22 \%$ had rapid GE. ${ }^{16,19}$ In our study, 23.2\% (37/159) diabetic subjects with chronic UGI symptoms had rapid GE, which was similar to the findings of previous studies.

GE disorders impact on substantial morbidity and quality of life in subjects with diabetes. ${ }^{8,20}$ Gastroparesis, defined as delayed GE in the absence of mechanical obstruction, leads to burden of health-care costs through frequent doctor visits, hospitalization and emergency room visits. ${ }^{8,21}$ In addition, Jung et al demonstrated that overall survival in subjects with gastroparesis was significantly lower than that of the general population, while there were inconsistent results in regards to mortality in patients with gastroparesis. ${ }^{22,23}$ Nevertheless, in both studies, coincident and major cause of death was cardiovascular disease, which is the most prevalent cause of morbidity and mortality in diabetic subjects. ${ }^{24}$ However, the relationship between GE time and incident cardiovascular disease in subjects with diabetes is unclear to date. Previously, Camurça et al ${ }^{25}$ reported that GE might be related to vascular dynamic change in animal models. Hyett et al ${ }^{8}$ suggested a correlation between diabetic gastroparesis and vascular complications including hypertension, coronary artery disease, and retinopathy. Kotani et al also showed that the GE $\mathrm{T}_{1 / 2}$ correlated positively with IMT of the carotid bulb and negatively with ankle brachial pressure index, which are risk indicators for future vascular disorders. ${ }^{26}$ In addition, the association of gastric motor disorders with diabetic autonomic neuropathy has been proposed. ${ }^{27}$ Another study showed that the type 1 diabetic subjects with cardiac autonomic neuropathy had more delayed GE than those without cardiac autonomic neuropathy. ${ }^{28}$ In our study, subjects with marked delayed GE had an increased incidence of cardiovascular events. Furthermore, in multivariate analysis, GE time was significantly associated with incidence of cardiovascular events after adjustment for comorbidities. In subgroup analysis, a significant association between GE and new-onset cardiovascular events was observed in subjects without previous history of cardiovascular disease. Therefore, although it is insufficient to draw causality between GE and cardiovascular events due to retrospective observation study and small number of sample size, our findings might give important information on the association between GE and cardiovascular events in Asian diabetic subjects with chronic UGI symptoms. However, we need to perform large scale and welldesigned cohort studies in the future.

In conclusion, a delay in GE was associated with incidence of cardiovascular events in diabetic subjects with chronic UGI symptoms. Even though conservative management is recommended, this study may warrant a more careful cardiovascular assessment with a high index of suspicion for possible events in management of diabetic subjects with a delay in GE.

Financial support: This research was supported by the National Research Foundation of Korea (NRF) grant funded by the Korea government (2018R1C1B5043483) and the Chonnam National University Hospital Research Institute of Clinical Medicine (CRI 18091-3).

\section{Conflicts of interest: None.}

Author contributions: Hyung-Min Park: analysis of electronic medical records and identification of patients for analysis; Jin Ook Chung: study concept and design, drafting and finalizing the manuscript; Seon-Young Park: study concept and design, analysis and interpretation of data, drafting and finalizing the manuscript, and study supervision; and Dong Hyuk Cho, Chang-Hwan Park, Hyun-Soo Kim, Dong Jin Chung, Sung-Kyu Choi, Jong-Sun Rew, and Min Young Chung: patient recruitment and care.

\section{References}

1. Krishnan B, Babu S, Walker J, Walker AB, Pappachan JM. Gastrointestinal complications of diabetes mellitus. World J Diabetes 2013;4:51-63.

2. Phillips LK, Deane AM, Jones KL, Rayner CK, Horowitz M. Gastric emptying and glycaemia in health and diabetes mellitus. Nat Rev Endocrinol 2015;11:112-128.

3. Iber FL, Parveen S, Vandrunen M, et al. Relation of symptoms to impaired stomach, small bowel, and colon motility in long-standing diabetes. Dig Dis Sci 1993;38:45-50.

4. Samsom M, Vermeijden JR, Smout AJ, et al. Prevalence of delayed gastric emptying in diabetic patients and relationship to dyspeptic symptoms: a prospective study in unselected diabetic patients. Diabetes Care 2003;26:3116-3122.

5. Horowitz M, Harding PE, Maddox AF, et al. Gastric and oesophageal emptying in patients with type 2 (non-insulin-dependent) diabetes mellitus. Diabetologia 1989;32:151-159.

6. Camilleri M. The stomach in diabetes: from villain to ally. Clin Gastroenterol Hepatol 2009; 7:285-287.

7. Vinik AI, Ziegler D. Diabetic cardiovascular autonomic neuropathy. Circulation 2007;115:387-397.

8. Hyett B, Martinez FJ, Gill BM, et al. Delayed radionucleotide gastric emptying studies predict morbidity in diabetics with symptoms of gastroparesis. Gastroenterology 2009;137:445-452.

9. American Diabetes Association. 8. Cardiovascular disease and risk management. Diabetes Care 2016;39(suppl 1):S60-S71.

10. Donohoe KJ, Maurer AH, Ziessman HA, Urbain JL, Royal HD. Procedure guideline for gastric emptying and motility. Society of nuclear medicine. J Nucl Med 1999;40:1236-1239.

11. Kim DH, Yun HY, Song YJ, et al. Clinical features of gastric emptying 
after distal gastrectomy. Ann Surg Treat Res 2017;93:310-315.

12. Seok JW. How to interpret gastric emptying scintigraphy. J Neurogastroenterol Motil 2011;17:189-191.

13. Expert Panel on Detection, Evaluation, and Treatment of High Blood Cholesterol in Adults. Executive summary of the third report of the national cholesterol education program (NCEP) expert panel on detection, evaluation, and treatment of high blood cholesterol in adults (adult treatment panel III). JAMA 2001;285:2486-2497.

14. Rose GA, Blackburn H. Cardiovascular survey methods. Monograph Ser World Health Organ 1968;56:1-188.

15. Saver JL. Proposal for a universal definition of cerebral infarction. Stroke 2008;39:3110-3115.

16. Bharucha AE, Camilleri M, Forstrom LA, Zinsmeister AR. Relationship between clinical features and gastric emptying disturbances in diabetes mellitus. Clin Endocrinol (Oxf) 2009;70:415-420.

17. Jones KL, Russo A, Stevens JE, Wishart JM, Berry MK, Horowitz M. Predictors of delayed gastric emptying in diabetes. Diabetes Care 2001;24:1264-1269.

18. Tack J, Bisschops R, Sarnelli G. Pathophysiology and treatment of functional dyspepsia. Gastroenterology 2004;127:1239-1255.

19. Bredenoord AJ, Chial HJ, Camilleri M, Mullan BP, Murray JA. Gastric accommodation and emptying in evaluation of patients with upper gastrointestinal symptoms. Clin Gastroenterol Hepatol 2003;1:264-272.

20. DiBaise JK, Patel N, Noelting J, Dueck AC, Roarke M, Crowell MD. The relationship among gastroparetic symptoms, quality of life, and gastric emptying in patients referred for gastric emptying testing. Neurogas- troenterol Motil 2016;28:234-242.

21. Camilleri M, Parkman HP, Shafi MA, Abell TL, Gerson L. Clinical guideline: management of gastroparesis. Am J gastroenterol 2013;108:1837.

22. Chang J, Rayner CK, Jones KL, Horowitz M. Prognosis of diabetic gastroparesis--a 25-year evaluation. Diabet Med 2013;30:e185-e188.

23. Jung HK, Choung RS, Locke GR 3rd, et al. The incidence, prevalence, and outcomes of patients with gastroparesis in Olmsted County, Minnesota, from 1996 to 2006. Gastroenterology 2009;136:1225-1233.

24. Matheus AS, Tannus LR, Cobas RA, Palma CC, Negrato CA, Gomes MB. Impact of diabetes on cardiovascular disease: an update. Int J Hypertens 2013;2013:653789.

25. Camurça FD, De Queiroz DA, Leal PR, et al. Gastric emptying and gastrointestinal transit of liquid in awake rats is delayed after acute myocardial infarction. Dig Dis Sci 2004;49:757-762.

26. Kotani K, Kawabe J, Kawamura E, et al. Clinical assessment of delayed gastric emptying and diabetic complications using gastric emptying scintigraphy: involvement of vascular disorder. Clin Physiol Funct Imaging 2014;34:151-158.

27. Guy RJ, Dawson JL, Garrett JR, et al. Diabetic gastroparesis from autonomic neuropathy: surgical considerations and changes in vagus nerve morphology. J Neurol Neurosurg Psychiatry 1984;47:686-691.

28. Darwiche G, Almér LO, Björgell O, Cederholm C, Nilsson P. Delayed gastric emptying rate in type 1 diabetics with cardiac autonomic neuropathy. J Diabetes Complications 2001;15:128-134. 